\title{
PROPOSIÇÃO DE UM REALISMO SEMIÓTICO PEIRCIANO PARA UMA DAS VERSÕES DA FÍSICA QUÂNTICA
}

\section{PROPOSITION OF A PEIRCEAN SEMIOTIC REALISM TO ONE OF THE VERSIONS OF QUANTUM PHYSICS}

\author{
Lino Machado \\ Ufes - Universidade Federal do Espírito Santo ${ }^{1}$
}

\begin{abstract}
RESUMO: Aplicação da semiótica triádica de C. S. Peirce à Mecânica Quântica, tal como estabelecida pela chamada Escola de Copenhague na década de 1920 e reinterpretada por Werner Heisenberg nos anos 1950, com o auxílio da noção aristotélica de dýnamis-potentia.

PALAVRAS-CHAVE: semiótica; filosofia; ciência; realismo.
\end{abstract}

ABSTRACT: Application of the triadic Semiotics by C. S. Peirce to Quantum Mechanics, as established by the so called Copenhagen School in the 1920's and reinterpreted by Werner Heisenberg in the 1950's, with the aid of the Aristotelian notion of dýnamis-potentia.

PALAVRAS-CHAVE: semiotics; philosophy; science; realism.

\section{Propósito do nosso trabalho}

No texto presente buscamos efetuar a inter-relação da noção filosófica de real de Charles Sanders Peirce e uma das versões da Física ou Mecânica Quântica (a da chamada Escola de Copenhague dos anos $1920,{ }^{2}$ na sua reconsideração por Werner Heisenberg, no decênio de 1950). Procedendo assim, o nosso estudo tem como objetivo geral o de apresentar um modelo de real multifacetado, resultante da combinação daqueles dois universos teóricos.

Cada um a seu modo, tanto Peirce como Heisenberg recuperaram a ideia de dýnamis (ou potentia), da Física e da Metafísica de Aristóteles: o norte-americano para elaborar a sua concepção de Primeiridade (no âmbito de uma reflexão triádica), o alemão para esclarecer o espinhoso conceito de "função de onda" da Mecânica Quântica, lançado na década de 1920 e repensado por ele nos anos 1950, com o aporte aristotélico a que referimos.

\footnotetext{
${ }^{1}$ Desde 1993 trabalha na Universidade Federal do Espírito Santo (Ufes), lecionando no Departamento de Línguas e Letras. Possui graduação em Português Literaturas (1979), mestrado em Literatura Portuguesa (1988) e doutorado em Literatura Portuguesa pela Universidade Federal do Rio de Janeiro (1996). Tem experiência na área de Letras, atuando principalmente nos seguintes temas: Literatura Portuguesa, filosofia e semiótica de Charles Sanders Peirce, intersemiose, diálogo literatura-artes visuais, intertextualidade e, em tempos mais recentes, filosofia da ciência. Além de artigos vários, publicou os livros As palavras e as cores, sobre Carlos de Oliveira (1999), e Sob uma capa (2010).

2 A denominação "Escola de Copenhague" pode ser enganadora, induzindo-nos ao erro de supor uma unidade de pensamento dos cientistas associados à mesma. Para acompanhar uma argumentação de que não existia tal unidade, cf. PINTO NETO, 2010, p. 7-9, 15-17. Manteremos, todavia, o nome consagrado. Outras versões dos fenômenos quânticos, que passaram a concorrer com a de Copenhague, também podem ser encontradas no detalhado livro desse autor.
} 
Em todo esse cotejo, a versão peirciana de categoria (Aristóteles de novo) ${ }^{3}$ é decisiva: nela se aloja a Primeiridade, noção sem a qual o nosso empreendimento seria impossível.

Um modelo de real (ou do que quer que se imagine) e um paralelo como o que já começamos a traçar aqui são exemplos complexos do que o próprio Peirce denominaria signos icônicos. Não espantará, portanto, que adiante esta conceituação ressurja (acompanhada, naturalmente, pelas de índice e símbolo). Não apressemos o passo, todavia, ou cairemos antes do final do trajeto, sob a não leve carga dupla que carregamos: a contribuição do filósofo norte-americano e uma das maiores revoluções da física moderna (ou, sem medo da generalização, de toda a história humana).

O paralelo aqui tentado estará sendo feito não a partir do formalismo matemático nem da experimentação, mas das conceituações (Terceiridades) presentes nos dois campos abrangidos. A nossa reflexão envolverá, por conseguinte, a linguagem, a discursividade, tendo em vista certa teorização semiótica, a qual segue mantendo o seu vigor no mundo contemporâneo. A questão do discurso verbal é, aliás, um ponto delicado em Física Quântica, tal como ressaltam os seus cientistas:

Werner Heisenberg estava inteiramente a par das dificuldades que encontraria para descrever o mundo subfenomenal [atômico e subatômico]. "Aqui, os problemas de linguagem são extremamente difíceis", disse ele. "Queremos falar [...] sobre a estrutura dos átomos [...]. Mas não podemos falar sobre átomos em linguagem comum" (HERBERT, 1989, p. 43, grifos nossos).

Veremos as razões de tais dificuldades e tentaremos contorná-las. Eis um desafio considerável: pretender transformar em texto, em enunciados discursivos o que, além de praticamente invisível aos nossos olhos, revela-se preso a lógicas bem diversas das que regem o nosso cotidiano, que não deixam de condicionar o modo como estruturamos os signos (os linguísticos, sobretudo). Muito diferente é o espectro quântico da realidade, com o qual pretendemos, apesar de tudo, dialogar.

\section{Charles Sanders Peirce, as suas três categorias e a sua semiótica}

O propósito do texto presente não estranhará os que possuírem um conhecimento mínimo de certos aspectos da biografia intelectual de Peirce. Além de haver sido matemático, o nosso autor criou tanto o chamado pragmatismo quanto uma versão completa da semiótica e, para além daquela vertente já clássica da filosofia, desenvolveu uma visão de índole triádica da realidade. Ele tinha um bom conhecimento do terreno das ciências do seu tempo - aliás, em tal terreno ele de fato labutou. Sabe-se que chegou a projetar "[...] um modelo de pêndulo [gravitacional], cuja precisão superava o europeu da época", de acordo com Renato Rodrigues Kinouchi, tradutor e prefaciador de textos do norte-americano para o português (PEIRCE, 2008, p. 9, n. 5).

Por sua vez, Haroldo de Campos lembrou que o único livro que Peirce publicou trazia as "[...] suas investigações astronômicas de mensuração da luz das estrelas, sob o título Photometric researches” (CAMPOS, 1986, p. 18-19). Ter lançado só um volume

\footnotetext{
${ }^{3}$ Aristotelicamente, as categorias são modalidades últimas de atribuição; "as noções mais gerais da filosofia" (GOBRY, 2007, p. 81). Séculos mais tarde, Kant ("analítica transcendental da Razão pura") e Hegel ("Lógica") criariam os seus respectivos sistemas de categorias (GOBRY, 2007, p. 82). Peirce os retomaria, com o seu pensamento triádico, mas também "neopitagórico".
} 
de autoria própria não o impediu de escrever um número enorme de páginas (cerca de 80.000 !), divulgando apenas algumas delas em revistas ou periódicos.

Ainda no prefácio de Kinouchi, lemos termos autodescritivos de Peirce, segundo os quais ele “[...] morou num laboratório desde [...] seis anos até bem depois da maturidade e, tendo [...] uma vida relacionada com experimentalistas, sempre teve a sensação de compreendê-los e de ser por eles compreendido" (PEIRCE, 2008, p. 9). Já não no prefácio citado, acha-se a seguinte passagem, também autorreferencial, de Peirce:

[...] minha filosofia pode ser descrita como a tentativa que um físico desenvolve no sentido de fazer conjetura acerca da constituição do universo, utilizando métodos científicos e recorrendo à ajuda de tudo quanto foi feito por filósofos anteriores. [...] O mais que se pode conseguir é fazer surgir uma hipótese não inteiramente despida de procedência, [...] na linha geral de desenvolvimento das ideias científicas e que seja suscetível de ver-se confirmada ou refutada por observadores futuros. (PEIRCE apud PIRES) ${ }^{4}$.

Peirce foi, pois, um físico do seu tempo e também um pensador, alguém que nos faz lembrar os inícios da filosofia grega, na sua feição pré-socrática naturalista e cosmogônica, depois assimilada por Aristóteles. Isto elimina a aparente estranheza do nosso paralelo da sua obra com a Mecânica Quântica, cotejo que deverá ter limites, devido à data da morte de Peirce (1914), a qual o impediu de ver a estruturação maior do "quantismo" (ocorrida, sobretudo, de 1925 a 27). Sem dúvida, tanto o tema da indeterminação, quanto a questão do possível (da dýnamis-potentia aristotélica, tal como revista por Heisenberg) dão uma boa base para um confronto produtivo da espécie que tentamos.

Uma esquematização das ideias do nosso pensador poderá ser útil. De início, ela apresentar-se-á com a "secura" que caracteriza os empreendimentos desse gênero até chegarmos aos pontos que nos mobilizam: as categorias e certas noções da semiótica que ele ideou, tratadas então com maior detalhamento. A sinopse apresentada não deixará de ressaltar a índole sistemática do autor. E ainda que só utilizemos parte dela, a sua explanação maior deverá conter algum valor didático, para leitores que se aventurem no universo peirciano, nem um pouco "econômico" nas suas reflexões.

Para Peirce, em sentido muito amplo, as ciências são práticas e teóricas. As ciências teóricas são heurísticas (ou da descoberta) e sistemáticas (ou da revisão). Há três classes de ciências heurísticas (ou da descoberta): 1) a matemática, que lida com hipóteses; 2) a filosofia, que trata da experiência direta, cotidiana, com as verdades positivas; 3) a ideoscopia (ou "ciência especial"), a qual labuta com observações especiais, mas partindo da vida diária.

No corpus peirciano, a filosofia se triparte em: 1) fenomenologia ou faneroscopia ou doutrina das categorias; 2) ciências normativas: estética, ética e lógica ou semiótica (gramática especulativa, lógica crítica e retórica especulativa); 3) metafísica: ciência do real subjacente às aparências. ${ }^{5}$ Irá evidenciar-se, adiante, que a tripartição presente dá alento a um cotejo entre o físico-pensador e a mecânica quântica, cheia de implicações filosóficas sobre a concepção de realidade (que ela revolucionou por completo, junto com a

\footnotetext{
4 "Panorama sobre a filosofia de Charles Sanders Peirce". Disponível em: www.unopar.br/portugues/revfonte/artigos/3charles/3charles.html. Acesso em: 14/07/2012, as 14h.

${ }^{5}$ Essa classificação subdivide-se mais, como demonstra o artigo eletrônico de Jorge Luiz Vargas P. de Barros Pires, referido por completo na nossa nota 3 (ao qual se pode acrescentar SANTAELLA, 1992, p. 116, 118 e 122). Para os objetivos do trabalho atual, todavia, não carecemos de um detalhamento (ainda) maior a respeito do assunto. Nem consideramos a evolução das ideias de Peirce ao longo da sua vida.
}

Disponível em: http://seer.fclar.unesp.br/casa 
Teoria da Relatividade Restrita, de 1905, e a Geral, de 1916, ambas produções de Albert Einstein).

Como ciência das aparências, a fenomenologia trata do faneron, isto é, segundo Peirce, "o total coletivo de tudo aquilo que está em qualquer momento presente na mente, sem qualquer consideração se isto corresponde a qualquer coisa real ou não" (apud HOOKWAY, 1985, p. 103).

Peirce distinguia três faculdades fenomenológicas: 1) ver sem interpretação o que se acha perante os olhos (Primeiridade); 2) discriminar aspectos do que se está observando (Secundidade); 3) ter a aptidão de generalizar, a partir do material observado (Terceiridade) (cf. IBRI, 1992, p. 5-6).

As três faculdades fenomenológicas implicam três categorias faneroscópicas (também tratadas por Peirce como "cenopitagóricas"), em geral traduzidas como: Primeiridade, Secundidade e Terceiridade. Aqui, vale a pena dar a palavra também ao pensador "neopitagórico", não apenas sintetizá-lo.

1) Primeiridade (Firstness): categoria que conglomera as noções de novo, existência, não constrangimento, diversidade, a qualidade do sentimento, a imediatez, sem fluxo de tempo.

A ideia de Primeiro predomina nas ideias de novidade, vida, liberdade. Livre
é o que não tem outro atrás de si determinando suas ações [...]. A Liberdade
só se manifesta na multiplicidade e na variedade incontrolada; e assim o
Primeiro torna-se predominante nas ideias de variedade sem medida e
multiplicidade. [...] O primeiro predomina na sensação, distinto da percepção
objetiva, vontade e pensamento. (PEIRCE/FREGE, 1983, p. 88)

2) Secundidade (Secondness): categoria reservada à experiência ainda não mediatizada do outro, da alteridade, dos fatos duros, dos dados brutos, requerendo os conceitos de reação, conflito, negatividade, existência, recortes de tempo e espaço definidos (passado e também o hic et nunc ou "aqui e agora").

A segunda categoria — o traço seguinte comum a tudo que é presente à consciência - é o elemento de conflito.

Está presente mesmo num fragmento rudimentar da experiência como uma sensação. A sensação tem sempre um grau de vivacidade, alto ou baixo, que é comoção, ação e reação, entre nosso espírito e o estímulo. [...] Ora, não há resistência onde não há conflito e ação de força. Por conflito, explico que entendo a ação mútua de duas coisas sem relação com um terceiro, ou medium, e sem levar em conta qualquer lei da ação.

$[\ldots]$

[...] A realidade é aquilo que insiste, nos força a reconhecer um outro diferente do espírito, e nela a Secundidade é predominante. (PEIRCE/FREGE, 1983, p. 90)

3) Terceiridade (Thirdness): categoria que busca dar conta da consciência, da aprendizagem, da aquisição de conhecimento, do fluxo temporal, da mediação.

Por terceiro entendo o medium, ou o vínculo ligando o primeiro absoluto e o último. [...] 
A ideia mais simples de Terceiridade dotada de interesse filosófico é a ideia de signo, ou representação. Um signo "representa" [stands for] algo para a ideia que provoca ou modifica. [...] O "representado" é o seu objeto; o comunicado, a significação; a ideia que provoca, o seu interpretante. $\mathrm{O}$ objeto da representação é uma representação que a primeira representação interpreta. [...]

Algumas das ideias de grande importância para a ciência e a filosofia onde a Terceiridade predomina são generalidade, infinidade, continuidade, difusão, crescimento e inteligência. (PEIRCE/FREGE, 1983, p. 92-93)

Como antecipamos, as três categorias são tão importantes (para a filosofia de Peirce e para os nossos propósitos) que merecem observações adicionais (achando-se mais discussão pormenorizada delas em IBRI, 1992, passim):

1) $\mathrm{Na}$ esfera da Primeiridade, o presente apenas vige como qualidade, sem as sensações de conflito.

2) No domínio da Secundidade, o ego e o não ego se opõem. O não ego é o mundo como exterioridade ou o tempo passado internalizado: ambos possuem a força do fato bruto. Ao ser generalizado, representado, mediatizado pelo pensamento, o passado faz-se ego, tornando-se inteligível no fluir do tempo (Terceiridade). E se Peirce afirma que, no real, "a Secundidade é predominante", esta não é ali exclusiva, pois nele a generalidade é fundamental.

3) Na área da Terceiridade, o ego é a instância da generalização, a qual se efetua a partir da dimensão factual da Secundidade, que pressupõe a Primeiridade.

A noção de real em Peirce exige reiteração dos seguintes pontos:

a) Mesmo que, em termos do predicado da existência, a Secundidade seja importante para a ideia de realidade, como vimos (e no que deveremos insistir), as duas outras categorias por igual a conformam.

b) A generalidade da Terceiridade é o que mais constitui o real, sendo lei subjacente aos fenômenos. Por sermos membros de uma espécie aptos a lidar com ela, fazemos previsões razoáveis (ou falíveis) sobre o futuro. A lei, que impõe consequências semelhantes sob situações semelhantes, todavia, não dá conta, com precisão total, da exuberância, da diversidade do universo (daí o "falibilismo" dos nossos parênteses, ao qual depois voltaremos).

c) Existem fatores decorrentes do acaso, da aleatoriedade, percebe-se a distribuição fortuita de componentes do mundo, notando-se a irregularidade de certas coisas: tudo isso impõe que se leve em consideração a Primeiridade para compreendermos o real. Essa categoria nos impede de ver o universo como algo regido de modo mecanicista, totalmente previsível nos seus desdobramentos (um dos aspectos que aproximam o peircianismo do quantismo, conforme iremos frisar).

Claro que a semiótica do filósofo se embasa no triadismo entranhado no seu pensamento. Ela é uma teoria, de caráter lógico-filosófico, que versa sobre as mais variadas modalidades de signos. Segundo uma das suas definições mais simples, um signo "[...] representa algo para alguém [...], cria na mente dessa pessoa, um signo equivalente, ou talvez [...] mais desenvolvido. Ao signo assim criado denomino interpretante do primeiro signo. $\mathrm{O}$ signo representa alguma coisa, seu objeto" (PEIRCE, 1977, p. 46, grifo nosso).

Quanto ao objeto, este se subdivide em imediato e dinâmico. Objeto imediato: o mais imediatamente disponível no signo (a sua concepção menos completa). Objeto dinâmico: o objeto (real ou imaginário) originador da semiose (ação dos signos), do qual, aos poucos ou mais rapidamente, vamos tendo percepção ou ideação de crescente nitidez. 
Quanto ao interpretante, este se triparte em imediato, dinâmico e final. Interpretante imediato: as possibilidades interpretativas do signo. Interpretante dinâmico: as possibilidades interpretativas efetivamente selecionadas no uso do signo. Interpretante final: o esgotamento das possibilidades interpretativas do signo (quando tal for possível) (cf. PINTO, 1995, p. 29-32 e 37-40).

Na prática, o objeto imediato e o interpretante dinâmico tendem a confundir-se. Sempre desenvolvemos interpretações específicas, singulares, localizadas de objetos que, focados, são já versões de algo.

Outros conceitos que requerem definição: o ícone, o índice e o símbolo, que concernem à tricotomia dos signos em relação aos objetos.

O traço definidor do ícone é a analogia, a similaridade dele com o seu objeto. Não é preciso que a semelhança entre ambos seja de caráter visual, nem tal semelhança desaparece caso ela seja "ajudada por regras convencionais" (PEIRCE, 1977, p. 65). São exemplos de ícones: quadros, desenhos, imagens, mapas, diagramas, esquemas, formulações matemáticas, onomatopeias, comparações, metáforas, etc. ${ }^{6}$

O que demarca o índice é o fato de ele apresentar alguma ligação direta, causal, com o seu referente: assim, estabelece com este um elo tão forte que nos atrai para a sua direção com certa facilidade. Um signo de tal estirpe aponta para algo ou o assinala. $\mathrm{O}$ elo referido decorre de características naturais; todavia, aceita-se que há relações indiciais baseadas em conexões fixadas culturalmente: ainda as "regras convencionais" de Peirce em atuação. Acham-se entre os índices, resultantes de ações naturais ou não: fumaça (sinal de fogo), pegadas, cata-ventos, sintomas, ponteiros de relógio, dedos apontando, setas, sinais de pontuação, numerais ordinais, pronomes pessoais, demonstrativos e relativos, advérbios de lugar e tempo, grifo e demais destaques de palavras, datações, nomes próprios, etc.

O que melhor singulariza o símbolo é a circunstância de ele remeter ao seu referente por convenção, lei imposta ou associação de ideias de índole arbitrária, como a maioria das palavras de uma língua, já que a união entre os significados e os significantes em geral não se baseia na similaridade (caso dos ícones) nem na contiguidade factual (caso dos índices mais "puros").

Podemos notar agora que as "regras convencionais" (que, mais acima, atuam na iconicidade e na indicialidade) revelam algo importante: a influência da simbolicidade nos dois tipos anteriores de signos. (Com efeito, na reflexão peirciana as três esferas categoriais agem umas sobre as outras, na medida em que formam uma totalidade, o que, neologicamente, denominamos uma "trirrealidade", a nosso ver compatível com as conquistas da física do século XX, desdobrando-se no nosso terceiro milênio).

Agora, eis um quadro, com as categorias e as tricotomias sígnicas de Peirce (e observe-se que a primeira e a terceira destas últimas apenas nele sintetizamos):

\begin{tabular}{|c|c|c|c|}
\hline $\begin{array}{c}\text { Categorias do } \\
\text { realismo peirceano }\end{array}$ & $\begin{array}{c}\text { Signo em relação a si } \\
\text { mesmo }\end{array}$ & Signo em relação ao objeto & $\begin{array}{c}\text { Signo em relação ao } \\
\text { interpretante }\end{array}$ \\
\hline PRIMEIRIDADE & qualissigno: & ícone: & rema: \\
\hline
\end{tabular}

\footnotetext{
${ }^{6}$ Embora admitamos que esses e outros exemplos simplifiquem o conceito de ícone, supomos que, para os propósitos do presente artigo, eles dão uma ideia suficiente do mesmo conceito. (Este lembrete vale para outras exemplificações, como a de índice, que aparece adiante.)

${ }^{7}$ Concedemo-nos a liberdade de criação neológica neste artigo, para lidar com o já ousado neologista que foi Peirce. Além disto, por causa do seu triadismo, ela se fará logicamente necessária, para além do seu aspecto linguístico-retórico.
} 


\begin{tabular}{|c|c|c|c|}
\hline $\begin{array}{c}\text { Qualidade } \\
\text { (Monadismo) }\end{array}$ & mera qualidade & $\begin{array}{c}\text { porta característica(s) do } \\
\text { objeto }\end{array}$ & possibilidade qualitativa \\
\hline $\begin{array}{c}\text { SECUNDIDADE } \\
\text { Experiência } \\
\text { (Diadismo) }\end{array}$ & $\begin{array}{c}\text { Sinsigno: } \\
\text { existente concreto }\end{array}$ & $\begin{array}{c}\text { índice: } \\
\text { tem relação existencial } \\
\text { com o objeto }\end{array}$ & $\begin{array}{c}\text { dicissigno ou dicente: } \\
\text { capaz de afirmação } \\
\text { signo de fato }\end{array}$ \\
\hline $\begin{array}{c}\text { TERCEIRIDADE } \\
\text { Lei }\end{array}$ & $\begin{array}{c}\text { legissigno: } \\
\text { lei geral }\end{array}$ & $\begin{array}{c}\text { símbolo: } \\
\text { tem relação arbitrária com o } \\
\text { objeto }\end{array}$ & $\begin{array}{c}\text { argumento: } \\
\text { signo de razão }\end{array}$ \\
\hline
\end{tabular}

Do que vimos até aqui, retenhamos, pois, as categorias triádicas e a classificação dos signos em relação aos objetos. Em seguida, passaremos ao indeterminismo. Depois será a vez de abordar a Mecânica Quântica, aqui e ali já com alguma observação peirciana. O passo final virá com a aproximação maior das concepções do nosso filósofo às conquistas (bastante inusitadas, em termos teóricos) de tal Mecânica.

A indeterminação é um elemento decisivo que, aos nossos olhos, justifica a aproximação da Escola de Copenhague (que estruturou a Física Quântica nos anos 1920) ao pensador norte-americano. Este aspecto fundamental foi detectado por Karl Popper. O indeterminismo viria a tornar-se um dos conceitos fulcrais da visão quântica, devido a Werner Heisenberg: em 1927, ele formulou o famoso princípio de indeterminação ou incerteza, que hoje carrega o seu nome. Popper viu a razoável semelhança (iconicidade) entre as postulações de um e as do outro: "[...] se é verdadeiro o indeterminismo de Peirce, ou de Heisenberg, ou alguma outra forma dele, então o puro acaso desempenha um papel principal em nosso mundo físico. Mas é o acaso realmente mais satisfatório do que o determinismo?" (POPPER, 1975, p. 198). Julgamos poder responder mais ou menos como Peirce o faria. Com o seu triadismo, ele diria que, como fator único, o acaso é insuficiente para justificar o "mundo físico", uma vez que, para possuirmos uma boa noção de realidade (de universo), necessitamos de três ingredientes: o referido acaso, a existência e a lei; apenas o primeiro não nos basta.

Para se ter uma imagem da gravidade do tópico acima, recordemos que Einstein não aceitava bem (ou por completo) a introdução do acaso, do aleatório na física, algo mais do que natural para Peirce. A Teoria da Relatividade Restrita e a Geral não incorporam o indeterminismo nas suas formulações, o que leva os cientistas a enxergá-las como Clássicas (embora tremendamente revolucionárias!) diante da Mecânica Quântica (cf. HAWKING, 2009, p. 60).

Algumas passagens peircianas revelam o seu próprio indeterminismo (o qual teve os seus predecessores). Para chegar às mesmas, precisamos recordar dois conceitos forjados pelo incansável classificador que foi Peirce: o tiquismo e o falibilismo.

O étimo do vocábulo de proveniência grega tiquismo significa acaso. Com ele o filósofo sublinhava algo, a saber, apesar de haver leis no cosmo, não se deve imaginá-las como infalíveis. Por quê? Por causa da variedade do real: ela implica imperfeição, impossibilidade de uma regularidade total na manifestação dos fenômenos. E fazemos parte disto: a possibilidade de errarmos, de nos equivocarmos na procura dos interpretantes corretos foi vista pelo pensador como um falibilismo ligado ao tiquismo, vale dizer, se também propendemos ao erro é porque vivemos mergulhados num "contínuo de incerteza e indeterminação" (PEIRCE apud IBRI, 1992, p. 52). Os dois grandes conceitos se acham correlacionados.

Eis agora um trecho de Peirce a respeito da atuação do acaso na realidade: 
É estranho como muitas pessoas terão uma dificuldade em conceber um elemento sem lei no universo, e que podem, talvez, ser tentadas a considerar a doutrina da regra perfeita da causalidade como uma das crenças instintivas originais [...]. Longe disto, ela é uma noção [...] absolutamente moderna, uma inferência perdida das descobertas da ciência. Aristóteles [Física 195b 31-198a 13] frequentemente afirma que algumas coisas são determinadas por causas enquanto outras ocorrem por acaso [tychê]. Lucrécio [De rerum natura: Livro II 1.216-93], seguindo Demócrito, supõe que seus átomos primordiais desviam-se de trajetórias retilíneas de modo fortuito, sem qualquer razão para tanto. Para os antigos, nada havia de estranho em tais noções; [...] estranho teria sido considerar que não havia acaso. Assim, não é necessário supor uma necessidade interna de crença na causalidade perfeita, se não encontramos quaisquer fatos para sustentá-la. (PEIRCE apud IBRI, 1992, p. 44: dest. nos.)

Neste ponto do nosso artigo, podemos encarar a problemática espantosa da Física Quântica. Óbvio que o item da indeterminação retornará.

\section{A Física (ou Mecânica) dos quanta}

"Mecânica quântica: matemática com magia negra." Albert Einstein

Há uma incrível história coletiva que conduz ao sarcasmo de Einstein aqui em epígrafe: história de que ele participou bastante, para aumentar a estranheza dos fatos, alguns dos quais recordaremos. (A Mecânica Quântica trata dos níveis atômicos e subatômicos da realidade, mas tenhamos em mente que nunca foi de fato traçada uma fronteira nítida entre o terreno quântico - ou micro - e a esfera não quântica - meso e macro - do real.) A história começa em 1900, com o cientista Max Planck. Naquela data, ele descobriu algo revolucionário em termos de ciência. Perante um problema que não precisamos detalhar tecnicamente neste contexto, a denominada "radiação do corpo negro", que não se explicava com a física formulada até o final do século XIX, Planck se valeu de uma noção sem sustentação no âmbito maior da episteme newtoniana da época: a hipótese de que a energia fluía não de modo contínuo, mas de maneira descontínua, discreta, em "pacotes", que ele nomeou quanta (o plural latino de quantum ou "quantidade").

A descoberta isolada de Planck elucidou matematicamente o problema técnico da "radiação do corpo negro", explicando os "dados experimentais obtidos em laboratório", que contrariavam, até aquele 1900, a ciência (OLIVEIRA; VIEIRA, 2009, p. 27). Uma novidade, porém, foi revelada pela natureza, por intermédio de Plank: a concepção de uma descontinuidade radical surgiu no horizonte teórico-prático do Homo sapiens. Na verdade, Planck descobriu, com o seu quantum, um novo (e esquisito) objeto dinâmico no âmago da energia. (Não espanta que, mais tarde, Heisenberg viesse a apontar "problemas de linguagem”, ao tratar do tema, como antecipamos: cf. HERBERT, 1989, p. 43).

A história imprevisível prossegue, entretanto. Em 1905, um (na época) desconhecido reutilizaria a noção de quantum, à qual não se concedia muita atenção, após a sua elaboração por Planck. Tentando responder a outra questão prática que permanecia insolúvel (a do "efeito fotoelétrico"), o jovem Einstein daquele ano a abordou por meio da hipótese de que a luz (também) se comportava como se feita de partículas (ou corpúsculos). A conjectura de a luz ser constituída por unidades discretas ou quantidades delimitadas (os 
quanta) contrariava o que fora estabelecido a partir do alvorecer do século XIX: a ideia de que a luz se compusesse tão só de ondas (depois da atuação brilhante de James Clerk Maxwell, ondas eletromagnéticas).

De início, muitos cientistas não aceitaram bem o insight einsteiniano (quântico); depois, contudo, eles admitiram dois pontos: a) Einstein estava correto, o que lhe trouxe o Nobel de 1921; b) a luz podia ser estudada quer como partícula quer como onda. Este segundo item passou à literatura científica com a designação dualidade onda-partícula, algo deveras estranho (quase "barroco"), que nos força a aceitar que uma única entidade tem predicados que parecem contraditórios: se a luz é feita de partículas, estas devem ser pensadas como coisas mais localizadas, como "grãos de areia"; se a luz apresenta características de ondas, elas se espalham de maneira difusa. Duas representações bem diversas de apenas um ente. ${ }^{8}$

Depois de Planck e Einstein, manifestou-se o físico dinamarquês Niels Bohr. Conta-se que, em 1913, ele sonhou com o modelo (ícone) do átomo, que existia já, em feitio de pequeno sistema solar. Por tal modelo (depois superado), os elétrons orbitariam os núcleos atômicos como "nanoplanetas" em volta de um "microssol". Precisava-se compreender o motivo de os elétrons não caírem no núcleo do átomo, como os nossos satélites artificiais acabam tombando na Terra. Para isto, Bohr lançou mão da estranhíssima ideia de "salto quântico". Este é sintetizado assim pelo físico Amit Goswami: "Uma transição descontínua de um elétron, de uma órbita atômica para outra sem passar pelo espaço entre as órbitas" (GOSWAMI, 2010, p. 332, grifo nosso). Com tais "saltos", os elétrons poderiam situar-se apenas em algumas órbitas dos átomos, não em todos os seus lugares.

Em 1924, o físico francês Louis de Broglie defendeu uma tese no mínimo tão revolucionária quanto as dos seus predecessores. Com o trabalho de Einstein de 1905 em mente, ele pensou numa ousada simetria: luz e matéria existem no nosso universo, a luz mostra uma conduta dual, ora comporta-se como onda, ora como partícula - então, por paralelismo ou analogia, a matéria também deveria ter um comportamento da espécie, às vezes atuando como partícula, em outras ocasiões como onda. (Eis um caso de iconicidade peirciana situado no seio da própria mãe-natura!). Não muito tempo depois (1927), a tese de Louis de Broglie (que se localizava apenas nos domínios icônico da matemática e simbólico da verbalidade, ou seja, Primeiridade e Terceiridade) veio a receber comprovação empírica (vale dizer, indicial ou de Secundidade).

Como o da luz, o conceito quântico de matéria implica, portanto, essa dualidade onda-partícula. Em 1926, o físico austríaco Erwin Schrödinger revelou até a matemática fundamental para o caso da matéria: a equação de "função de onda". Esta matemática viria a mostrar-se compatível com outra, muito diversa, elaborada para os quanta: a de Heisenberg, de 1925, conhecida como Mecânica das Matrizes ou Matricial. (Duas formulações sígnicas diferentes para um mesmo objeto dinâmico, diríamos, à maneira peirciana.) A criação de Schrödinger tornou-se a Mecânica Ondulatória.

Para efeito de similaridade (de modelo), partícula é comparável ao que, na experiência cotidiana, imaginamos ser a matéria: algo definido, pontual, localizado, como um corpo enorme (um edifício) ou uma coisa mais "granular" (uma sementinha). Onda (ou função de onda ou onda de possibilidade) é aqui uma entidade sem similar: não é um

\footnotetext{
${ }^{8}$ Geraldo A. C. Tupynambá resume bem a questão: “Ondas se confundem com partículas. No entanto, as qualidades de partícula nunca se mostram simultaneamente com as de onda. Não se trata de uma idiossincrasia física. É antes uma incapacidade de a mente conceber essa combinação. As qualidades isoladas ora levam a uma imagem, ora a outra. Juntas formam uma figura incompreensível” (TUPYNAMBÁ, 2006, p. 214).
} 
elemento físico, pois, quando tem um comportamento de onda, a matéria é "mera" possibilidade (superposição, coexistência de estados ou localizações da matéria ordinária), ou seja, algo ainda não físico, que vige não no nosso espaço quadridimensional (espaço-tempo einsteiniano), mas sim num espaço especial chamado "de Hilbert" (em homenagem ao importante matemático dos séculos XIX e XX), com múltiplas dimensões. Quem deu tal interpretação probabilística à "função de onda" de Schrödinger foi o alemão Max Born já em 1926. E o próprio Schrödinger não se alegrou com o detalhe de que a sua função de onda dissesse respeito não a ondas físicas de fato (como ele pressupusera de início), mas a probabilidades de a matéria estar cá e lá no universo. Como Planck e Einstein, aliás, ele se arrependeu por haver contribuído para o estabelecimento da doutrina quântica.

Além dos cientistas citados, outros, como Paul Dirac e Wolfgang Pauli, tomaram parte nesse desconcertante processo. Já sabemos que o agrupamento desses físicos ficaria celebremente conhecido como Escola de Copenhague, em referência a Niels Bohr, de nacionalidade dinamarquesa: menos jovem do que os outros, Bohr os liderava. Tal escola se apresentou mais estruturada ao mundo em outubro de 1927, no Congresso de Solvay, em Bruxelas, ainda sem a sua famosa denominação (também conhecida como Interpretação de Copenhague ou Versão Ortodoxa da Física Quântica).

Quais os postulados da escola em causa? Segundo eles, a energia é algo discreto, descontínuo; os quanta são duais (ondulatórios e corpusculares); até que seja feita uma observação (ou medição), a matéria "existe em todos os estados possíveis simultaneamente" (KAKU, 2007, p. 152, grifo nosso). Queremos saber o estado desses objetos? Então somos obrigados a observá-los, o que induz tal coexistência de possibilidades (a sua função de onda) a adquirir definição, limites - algo que, no jargão dos físicos, chamase "colapso da função de onda" ou "redução de estado". Enquanto não se der tal colapso, a existência de "todos os estados possíveis" vige em superposição.

Quando nos aproximamos da área dos quanta, produzimos uma interferência inevitável. Sabemos que ela foi até matematizada por Werner Heisenberg em 1927, no princípio da incerteza ou indeterminação: este afirma que nunca se terá um conhecimento completo da natureza, pois, ao se conhecer um aspecto da esfera quântica, altera-se o seu estado em algum ponto importante, quer o pretendamos quer não. Trata-se de uma interferência física na realidade, não de uma limitação subjetiva e/ou ideológica latente em qualquer interpretação de dados do mundo. Em termos peircianos, tudo se passa como se o real dos quanta impedisse um interpretante final, ocasionando interpretantes dinâmicos imprevistos a cada nova medição.

Admitimos que a indeterminação de Peirce e a de Heisenberg não sejam noções "sinonímicas". Ainda assim, apesar da razoável dessemelhança que há entre uma posição filosófica que buscou incorporar ao seu arcabouço teórico o acaso, a novidade, o imprevisto (o tiquismo peirciano) e o indeterminismo de uma ciência dirigida a uma região do real envolvendo pares de grandezas conjugáveis (como ocorre na microdimensão dos quanta), pensamos que a aproximação dos dois campos em debate é instigante o suficiente para ser levada a efeito. Não por acaso vimos antes Popper falar no "indeterminismo de Peirce, ou de Heisenberg", o que aponta para certa semelhança entre ambos, não negligenciável...

Queremos chegar a um realismo peirciano-quântico, combinando os nossos dois universos teóricos. Antes, todavia, precisamos encarar a séria hipótese do anti- ou (ao menos) não realismo que emerge da microfísica, mormente quando associada à Escola de Copenhague.

São de um importante cientista brasileiro, Ivan S. Oliveira, em artigo intitulado "Revisitando a estranha natureza da realidade quântica", algumas das afirmativas mais 
impressionantes que lemos sobre o assunto (dignas de serem repetidas, pelo seu caráter tanto lapidar quanto pelo seu teor surpreendente):

Desse tipo de descrição [da matéria], resulta um quadro [...] estranho [...]. Por exemplo, objetos [...] como elétrons, prótons e átomos [entre outros] não têm um lugar definido no espaço. De fato, é necessário supor que esses objetos não tenham a propriedade de "estar em algum lugar", a menos que se faça um experimento para se observar sua posição.

$[\ldots]$

O mesmo acontece com [...] propriedades físicas [...] como a energia e a velocidade. Segundo a mecânica quântica, não tem sentido físico [...] imaginar que um elétron [...] "esteja em algum lugar" bem definido, nem mesmo tenha certa energia e velocidade, propriedades que [...] poderíamos atribuir à Lua [...] em torno da Terra.

[...] Em outras palavras, a mecânica quântica nos diz que as propriedades físicas dos objetos dependem da observação.

A ideia oposta - ou seja, a de que os objetos físicos têm propriedades físicas como posição, energia, velocidade etc., independentes da observação - é chamada de realismo.

A mecânica quântica, portanto, é uma teoria não realista. ${ }^{9}$

O não realismo da Física Quântica divide os próprios cientistas, como, aliás, sabe o competentíssimo Ivan S. Oliveira. Um detalhe é inegável aqui, todavia: a implicação de inseparabilidade, assim expressa por Amit Goswami: "Falar em objeto quântico sem falar sobre a maneira como o observamos é ambíguo, porque os dois são inseparáveis" (GOSWAMI, 2010, p. 66: destaques nossos).

Apesar de tudo (ou do risco de não realismo), explicitemos, ainda mais, a nossa preferência pela versão da "Escola de Copenhague", a que afinal se atém Ivan S. Oliveira. Em artigo datado de 2001 ("O sujeito na física quântica"), por sua vez o físico e filósofo das ciências Osvaldo Pessoa Jr. faz um detalhado balanço do que, até aquele ano, foi efetuado, em termos da difícil tarefa de exegese da Mecânica Quântica. Conclui ele assim (com palavras que, em 2013, preservam a sua atualidade): "O que temos hoje como consenso consiste da velha interpretação ortodoxa, [...] extirpada de boa parte de seus elementos idealistas originais mas mantendo sua postura instrumentalista (de rejeição à 'conversa fiada' filosófica de entidades não observáveis), e remendada com diferentes novidades teóricas [...]" (dest. nos.). ${ }^{10}$

De um modo ou de outro, quando se tenta superar tal "interpretação ortodoxa" (de Copenhague), muitíssimo dela persiste. Precisamente partindo desta versão que parece não perder a sua força (para além da mera questão de um "classicismo" cronológico seu), almejamos sair da "postura instrumentalista" acima aludida, buscando uma alternativa filosófica realista para a problemática envolvendo o quantum.

Se uma das coisas que perturbaram Einstein na Física Quântica foi a surpreendente não serventia do mecanismo da causalidade nos seus domínios, outro item que o incomodava era que, na sua sondagem da natureza dos mundos atômico e subatômico, a

\footnotetext{
${ }^{9}$ Disponível em: http://cienciahoje.uol.com.br/revista-ch/2011/282/revisitando-a-estranha-natureza-da-realidadequantica. Acesso em: 06/09/2011, às 21h.

${ }^{10}$ Disponível em http://www.fflch.usp.br/df/opessoa. Acesso em 21/05/2013, às 10h. Ressalte-se que Osvaldo Pessoa Jr. não se furta ao debate das questões filosóficas da Mecânica Quântica: ao contrário, dedica-se com afinco ao mesmo (cf., por exemplo, PESSOA Jr., 2003, passim).
} 
teoria que, no início, ele ajudou a criar tendia para a postulação de que não existem propriedades físicas que sejam independentes das observações (medições) que delas façamos. De novo em termos peircianos, tudo se passa como se, no reino dos quanta, os nossos interpretantes afetassem fisicamente os objetos dinâmicos que buscássemos observar.

A segunda preocupação einsteiniana acima sempre requer atenção demorada.

Todos e tudo estamos "aqui" afinal, bem definidos e localizados (ao menos em aparência). Por que não nos achamos "esparramados" (valha a metáfora) num espaço multidimensional, com diferentes probabilidades de ser, tal como pode sugerir certa leitura da Mecânica que abordamos? ${ }^{11}$ Em terminologias de Peirce e da Física, por que então nos encontramos tão bem situados (ou mal, em balizas sociais) na Secundidade clássica, não na Primeiridade das possibilidades quânticas, aguardando que alguém nos observe?

A Teoria da Descoerência (ou Decorência), cuja discussão se iniciou no final dos anos 60 com Hans Dieter Zeh (FREIRE Jr. in: FREIRE Jr. et al., 2010, p. 36-40), dá uma possível resposta para a questão acima. Segundo tal teoria, o meio-ambiente, a natureza, ou seja, em última instância, o próprio universo provoca os colapsos da função de onda. A descoerência requer a noção de coerência quântica: esta, em brevíssimas palavras, ocorre quando as ondas dos quanta se acham interligadas ou os seus componentes existem em uníssono, em cooperação - algo próprio dos esdrúxulos fenômenos que vamos observando. Uma interação desses fenômenos com o restante do universo cancela as suas características quânticas mais esquisitas, como, por exemplo, a possibilidade de uma única partícula estar em vários lugares ao mesmo tempo, por obra e graça da sua função de onda.

A descrição anterior faz ver que o próprio meio-ambiente (Secundidade) induz as coisas deste mundo a terem um comportamento ou um modo de ser comum, newtoniano, igual ao que percebemos no cotidiano, com as nossas limitações sensoriais. Com isto, ficaria sanada a questão referente à passagem de um estado quântico a um clássico; não necessitaríamos preocupar-nos com a exigência de uma onda de possibilidades ser observada por algum ser vivo, para "saltar" da sua condição de superposição de estados e se localizar num "aqui e agora" pontual.

Segundo os físicos, essa teoria se mostrou uma linha de pesquisa válida na área quântica, mas apresenta o seu limite, pois não resolve o problema da necessidade da medição de partículas isoladas, que seguem exigindo uma intervenção nos moldes de Copenhague. Em conceituação perciana, afirmaríamos: a Secundidade (descoerência) restringiu o âmbito da Primeiridade (onda de possibilidade), mas não o aboliu.

Outro jeito de descrever tudo isto: partículas isoladas têm, sim, uma conduta bizarra, mas, logo que várias interagem umas com as outras, o seu modo de ser tende para um "comportamento médio", vale dizer, os mecanismos ou leis (Terceiridade) do reino atômico e subatômico de possibilidades (Primeiridade) permitem que estejamos aqui, bem situados e definidos (Secundidade): "O mundo clássico em que vivemos é uma média, um mero caso particular do mundo quântico. Assim, podemos ver a indeterminação quântica como uma forma extremamente criativa de tornar determinístico o movimento de objetos clássicos" (OLIVEIRA, VIEIRA, 2010, p. 45). Luminosa explicação!

Há nova maneira de redefinir tudo acima. Assim, a causalidade clássica, as conexões de causa e efeito, o determinismo (Terceiridade causal) existem sobre uma base indeterminista mais fundamental, em que um sem-número de possibilidades (Primeiridade)

\footnotetext{
${ }^{11}$ De certo modo, a versão da Física Quântica apresentada por Hugh Everett III, em 1957 ("Relative state" formulation of quantum mechanics, nos anos 70 rebatizada como "many-worlds interpretation") segue na incrível direção de uma multiplicação de realidades (universos) a cada evento quântico do cosmo (cf. PINTO NETO, 2010, p. 73-88)!
} 
coabitam, até estas virem a sofrer "estreitamentos" que, na história do universo, tornam-nas atuais (Secundidade).

Aqui e ali, na presente seção, usamos o jargão de Peirce, em articulação com a lógica dos quanta. Passemos a um paralelo menos pontual ou de maior amplitude.

\section{Peirce e a Física Quântica}

Insistimos que, para Peirce, a Primeiridade e a Terceiridade são reais na sua esfera própria, tanto quanto a Secundidade captada pelos nossos sentidos, não importando que aquelas duas realidades (ou aspectos da "trirrealidade" maior) tenham naturezas bem diversas das que, em geral, atribuímos ao universo efetivo, condicionados como vivemos aos dados fenomênicos da segunda categoria (da existência, não da generalidade - e esta é fulcral para o nosso filósofo).

Via de regra, acredita-se no seguinte: o primeiro e o terceiro conceitos não passam de construções intelectuais, abstrações cômodas, idealizações necessárias, ficções teóricas, mas irreais em termos ontológicos, já que não relacionadas a unidades concretas. Peirce pode, todavia, estar certo ao pensar a realidade como algo triádico, caso argumentemos com a lógica de Física Quântica, mormente a da Escola de Copenhague (acrescida do mecanismo da descoerência). No âmbito dela, descobriu-se a dualidade onda-partícula, que também define a luz, como Einstein começara a notar a partir de 1905.

Para tentar desenvolver o nosso raciocínio, retomemos a superposição quântica, redescrevendo-a com novos signos. Fazendo uso tão só de dois fatores informacionais (0/1), vejamos em termos sintéticos o que é um quantum, confrontando-o com coisas comuns, visualizáveis, chamadas "clássicas" (cf. SEIFE, 2010, passim).

Um macro-objeto clássico existe cá (0) ou ali (1), não em dois locais ao mesmo tempo: exemplo de lógica binária (alternativa 0 ou 1, um bit da Teoria da Informação Clássica), que atua no nosso cotidiano. Um objeto atômico ou subatômico (um quantum) é diverso, contudo, pois, antes de alguma medição, tem a possibilidade de achar-se aqui (0) e ali (1) ao mesmo tempo (superposição 0 e 1, um q-bit da Teoria da Informação Quântica, em evolução desde a década de 1970). Como afirma John Polkinghorne: "Se a teoria quântica está, de fato, dizendo-nos como o mundo atômico realmente é, então sua realidade é algo muito diferente da objetividade ingênua com a qual podemos abordar o mundo dos objetos cotidianos" (POLKINGHORNE, 2011, p. 101, grifo nosso).

Sendo feitos da matéria conhecida do universo (quarks, glúons, elétrons, etc.), cada um de nós é formado de elementos que têm esse duplo caráter: ou são fatores localizados aqui e agora (0 ou 1), classicamente detectáveis, ou "somente" possibilidades de ser (0 e 1), quanticamente falando. Os objetos do mundo aos quais, via de regra, atribuímos a total realidade surgem destas possibilidades, que, no esquema peirciano do real, não é mais do que parcela (Secundidade) de um todo - de uma totalidade triádica ao menos.

E quanto à problemática do realismo, que, após o nosso resumo da Mecânica Quântica, de fato parece ficar em má situação filosófica?

Não olvidamos a afirmação de não realismo defendida por Ivan S. Oliveira para a área quântica, mas ela é polêmica já nesse campo (retome-se a citação de Polkinghorne mais acima, em especial a sua menção a "como o mundo atômico realmente é"). No Brasil, Osvaldo Pessoa Jr. é dos físicos que afirmam:

[...] queremos apenas sublinhar que quem morreu [...] não foi o realismo em geral, mas um certo tipo que chamaremos de realismo classicista, a tese de 
que a realidade tem uma estrutura próxima às nossas concepções e intuições clássicas a respeito do mundo" (PESSOA Jr., 2003, p. 104, grifo nosso).

Tal "realismo classicista" foi também o de Einstein, em suas críticas à Mecânica Quântica, vale dizer, a suposição de que a matéria não depende da observação. Ao que parece, porém, se atentarmos para o que ocorre na área quântica, as coisas não se passam de todo assim, ora requerendo a noção de coerência (Primeiridade), ora a de descoerência (Secundidade). De novo, citemos Osvaldo Pessoa Jr., em seu artigo de 2001: “[...] ao final de 75 anos de Mecânica Quântica, o sujeito epistemológico ainda não conseguiu ser exorcizado da teoria". ${ }^{12}$ Certo, o autor fala aqui em "sujeito epistemológico" (ou do conhecimento), não em "sujeito ontológico", mas aquele já coloca problemas sérios para um realismo ("classicista") como o de Einstein.

O realismo de Peirce é marcado pela apropriação medieval (ou escolástica) de Aristóteles: baseia-se na suposição da realidade dos universais, em oposição ao nominalismo, segundo o qual, grosso modo, apenas existiriam coisas particulares (nomeadas por signos, que nos "iludiriam", quando remetessem a ideias gerais, induzindo-nos a enxergá-las como também reais). Embora a postura escolástico-aristotélica peirciana não seja aceita facilmente nos tempos modernos (pós-medievais), mais afeitos a um modo de pensar nominalista (típico, por exemplo, da Linguística de Saussure e da semiótica que dela se derivou, ambas muito pautadas pela ênfase na arbitrariedade dos signos), supomos ser exatamente o pensamento triádico do autor norte-americano um dos mais aptos a fornecer suporte a uma noção não "classicista" de realismo: em síntese, um realismo que dependa da exigência de observação dos objetos atômicos e subatômicos, para que estes ganhem "propriedades físicas"13. Isto requer algo: que se incorpore o nível da função de onda à nossa concepção de universo, não sendo aquela função considerada apenas uma ferramenta matemática apropriada para fazer cálculos sobre as partículas. Lemos antes: "A realidade é aquilo que insiste, nos força a reconhecer um outro diferente do espírito, e nela a Secundidade é predominante" (PEIRCE/FREGE, 1983, p. 90). Pois bem: para além (ou aquém) da Secundidade, a função de onda do quantum (Primeiridade) também "insiste", é um "outro diferente do espírito", por mais que este nela interfira, quando lida com a mesma!

Em termos científicos, estranhezas como as enunciadas acima são chamadas pelos físicos de contraintuitivas, o que equivale a dizer que elas são bastante divergentes de tudo o que, em interação coletiva, ao longo da história, o bom senso, o testemunho dos sentidos (entre os quais o da visão foi privilegiado), as tradições antigas do saber estabeleceram.

Por seu turno, em boa parte do terreno da filosofia da modernidade, a crença peirciana na realidade da Primeiridade e da Terceiridade segue na contramão (diverge) do materialismo difuso (por vezes marxista, ou diluidamente marxista) que tomou a nossa cultura, embora sem destruir de todo as suas bases religiosas, num processo para o qual contribuiu o triunfo da Física (hoje) Clássica (pré-quântica) de Copérnico, Kepler, Galileu, Newton, Maxwell e o seu revolucionador Einstein, ficando entre os muito lembrados...

Esclareçamos mais o nosso paralelo. Chegamos, aliás, aos seus pontos decisivos.

\footnotetext{
${ }^{12}$ Disponível em http://www.fflch.usp.br/df/opessoa. Acesso em 21/05/2013, às 11h.

${ }^{13}$ Não temos mais como continuar nos limites da noção de realismo que predominou na nossa tradição (clássica, pré-quântica). Se persistirmos nele, não escaparemos da tremenda afirmativa de Ivan S. Oliveira. Um realismo peirciano-quântico é um realismo também de Primeiridade (e de Terceiridade, claro, sem precisarmos enfatizar o óbvio papel da Secundidade nele).
} 
Acreditamos que a Primeiridade de Peirce tem correspondência no terreno das funções de onda ou ondas de possibilidade, com vigência no espaço de Hilbert; a Secundidade, no domínio das partículas detectadas; a Terceiridade, no campo das leis que regem as Físicas Quântica e Clássica: a zona das generalidades, a mesma que, para o filósofo norte-americano, é o modo máximo de manifestação da realidade, mais do que construção intelectualizada de seres como os humanos. Em reflexão triádica, o cérebro, com os seus tecidos, células, etc., é real; o pensamento, não menos. Caso defendamos o contrário, lancemos a mente no reino do "sobrenatural"... A defesa da sua realidade não quer dizer que tudo o que ela vem a idear é "verdadeiro", "evidente", "natural", dada a nossa tendência ao falibilismo, por causa do tiquismo universal, com o seu tecido "de incerteza e indeterminação", do qual participamos. Sim, até ao "errarmos feio", estamos atuando de acordo com a tessitura (triádica) do real (concepção que, levada a sério, quiçá nos livre das armadilhas do relativismo, do nominalismo, etc.).

Em visão peirciana, a Terceiridade não é só ficção teórica, simples construto mental (discursivo, formal, ens rationis), utilíssimo para a compreensão humana do universo natural e social, mas despojado do traço de realidade, em geral restrito à concretude dos objetos do mundo. De modo algum: para o nosso filósofo, a Terceiridade é real (ens reale) - e assim ele pende para o idealismo objetivo, onde se encontram Platão e Hegel, cada um a seu modo. (Raciocínio semelhante seria aplicável à valorização realista de Peirce da Primeiridade.)

Avancemos mais.

Quando lidou com a primeira categoria, o autor norte-americano valeu-se da noção de dýnamis (ou potentia), da Física e da Metafísica de Aristóteles, entre mais tradições (como as de Kant e Hegel).

Tendo em mente os propósitos (e os limites de página) do presente artigo, não necessitamos mergulhar na rica ontologia aristotélica, no seu vasto corpus textual, sempre dependente da interpretação dos seus inúmeros exegetas, dada a distância histórica entre a época grega e a nossa, por mais que esta deva àquela (cf. BITTAR, 2003, passim, espec. p. 933-937). Nem Peirce nem Heisenberg pretenderam importar a completa filosofia de Aristóteles, concentrando-se no essencial dela que lhes interessava.

Baste-nos lembrar aqui o seguinte: para o Estagirita, se quisermos entender a ousía (substância, matéria e forma, o composto destas duas), precisamos recorrer, entre outras noções, ao binômio dýnamis (potência) e enérgeia (ato, processo). O ser é em potência e em ato. A potência explica o movimento, as mudanças físicas do mundo. Trata-se da capacidade, da força, da faculdade das coisas. Passa-se de um estado potencial a um atual. Quando se atinge a atualidade plena, perfeita, consumada, Aristóteles se vale não mais do termo enérgeia, porém do vocábulo entelékheia. (O Estagirita não deixa de utilizar as duas últimas palavras como sinônimas, todavia.) A enérgeia também pode ser vertida como "atividade motriz"; a entelékheia, como "acto perfeito ou completo" (MESQUITA, 2005, p. 500).

Interessante que, em certos contextos da massa aristotélica de escritos, dýnamis seria traduzível como "qualidades" ou "propriedades" (MESQUITA, 2005, p. 501, n. 55). Em conversão peirciana, a dýnamis transformar-se-ia em Primeiridade; tanto a enérgeia quanto a entelékheia, em Secundidade (aquela uma Secundidade menos consumada do que esta).

Ao que parece ignorando Peirce (autor bem pouco divulgado internacionalmente, antes dos anos 1970), Werner Heisenberg lançou mão por igual da noção de potentia na década de 1950, tentando alargar a nossa concepção de real, no interior da Física Quântica, pois ele buscava acrescentar algo decisivo à anterior formulação da Escola de Copenhague. Um livro do cientista que contém não poucas referências à potentia é Física e 
filosofia (HEISENBERG, 1999, p. 61, 78, 81, 206 e 222). F. S. Northrop, o prefaciador da edição norte-americana de 1962 da obra, chega a afirmar: "A tese mais nova e importante deste livro talvez seja a afirmação [...] de que a mecânica quântica reviveu o conceito aristotélico de potencialidade [...]. Consequência disso é que a mecânica quântica é igualmente importante para a ontologia e a epistemologia" (in: HEISENBERG, 1999, p. 1314: dest. nos.).

O mesmo prefaciador ressalta que suposições de caráter ontológico "referemse ao objeto do conhecimento científico, o qual é independente do observador", ao passo que as de cunho epistemológico "referem-se à relação entre o cientista, como experimentador e conhecedor, e o objeto que conhece" (in: HEISENBERG, 1999, p. 13). Ora, a Física Quântica torna pouca nítida a distinção entre uma esfera filosófica e a outra, sobretudo devido ao princípio da indeterminação do próprio Heisenberg, situação na qual toda e qualquer intervenção do sujeito examinador interfere bastante no objeto por ele visado.

Quanto à tentativa heisenberguiana de rever a potencialidade aristotélica, nos seus valiosos Conceitos de física quântica, Osvaldo Pessoa Jr. assim a esclarece:

Heisenberg desenvolveu, nos anos 50, uma interpretação que enfatizava alguns pontos não desenvolvidos por Bohr. [...] Heisenberg passou a sustentar que a função de onda [...] exprime uma potencialidade, no sentido aristotélico, relacionada a uma propriedade "objetiva" que independe do estado de conhecimento do observador. [...] A respeito dos "saltos quânticos" (colapsos), da "transição do 'possível' ao 'real' [que] ocorre durante o ato de observação", Heisenberg [...] enfatizou que ela "toma lugar tão logo a interação do objeto com o instrumento de medida (e, portanto, com o resto do mundo) tenha se realizado". (PESSOA Jr., 2003, p. 96, grifo nosso)

Eis alguns passos em que Werner Heisenberg expõe o seu "neoaristotelismo quântico", por assim dizer:

[...] Nas experiências relativas aos eventos atômicos devemos lidar com coisas e fatos, com fenômenos que são tão reais quanto os fenômenos da vida diária. Porém, os átomos e as partículas elementares não são assim tão reais; eles formam um mundo de potencialidades ou possibilidades, e não de coisas ou fatos... A onda probabilística... significa uma tendência para alguma coisa. Ela é uma versão quantitativa do velho conceito de potentia, da filosofia de Aristóteles. Ela introduz algo que está entre a ideia de um evento e o evento propriamente dito, um estranho tipo de realidade física, entre possibilidade e realidade. (HEISENBERG apud HERBERT, 1989, p. 43)

Por passagens do teor da supracitada, o físico Nick Herbert usou as expressões "mundo duplo" e "os dois mundos" de Heinsenberg: nas "experiências relativas aos eventos atômicos", haveria o "mundo de potentia" (ou "de potencialidades"), por um lado, e o de "realidades" (o "nosso mundo"), por outro lado, conectáveis pelas medições efetuadas pelos cientistas (HERBERT, 1989, p. 42-44). Embora a retomada do conceito de dýnamis-potentia de Aristóteles nos pareça correta, já não nos soa apropriado forjar um binômio "potencialidade"/"realidade", que, devido a tal oposição, deixaria a "potencialidade" desprovida do traço de "realidade". O próprio Heisenberg parece hesitar na sua argumentação: primeiro, ele escreve que "os átomos e as partículas elementares não são assim tão reais"; em seguida, afirma que a "onda probabilística" (uma "versão quantitativa do velho conceito de potentia", criada afinal para dar conta das "partículas elementares") é um "estranho tipo de 
realidade física, entre possibilidade e realidade"... Estamos aqui perante um triadismo heisenberguiano mal equacionado em termos verbais ("possibilidade", "estranho tipo de realidade física" e "realidade")? Induz-nos a pensar que sim o comentário crítico, feito por John Polkinghorne, em Teoria quântica, à mesma passagem do grande físico alemão. Eis o comentário aludido:

Um elétron [como as demais partículas] não possui, o tempo todo, uma posição definitiva ou um momentum definitivo [quantidade de movimento]; em vez disso, ele possui a potencialidade de exibir um ou outro [0 ou 1] se uma medição transformar a potencialidade em realidade. Eu discordaria do raciocínio de Heisenberg de que esse fato torna um elétron "não tão real" quanto uma mesa ou uma cadeia. O elétron simplesmente goza de um tipo distinto de realidade, apropriado à sua natureza. Se formos conhecer as coisas como elas são, devemos estar preparados para conhecê-las como realmente são, em seus próprios termos, por assim dizer (POLKINGHORNE, 2012, p. 102, grifo nosso)

Dialoguemos, semiótica e faneroscopicamente, com o trecho citado. Peirce chamaria cada um dos elementos atômicos e subatômicos, oriundos de observações efetuadas em geral nos laboratórios (elétrons e mais partículas, falíveis que sejam estas noções enquanto fatores interpretáveis), de objetos dinâmicos (embora estranhos, com os seus "tipos distintos de realidade"). Os "próprios termos" de tais elementos caracterizariam os interpretantes (imediatos e dinâmicos, ao menos). Os nomes, as sentenças em que se insiram e, sobretudo, o formalismo matemático com os quais os físicos lidem seriam os signos (simbólicos os primeiros, icônicos os segundos, preponderantemente). Eis o que podemos tratar como um trirrealismo peirciano, quase de todo compatível com a formulação acima de Polkinghorne. Por que a nossa modulação (quase pedante) do "quase"? Porque, apesar de divergir de Heisenberg (supomos que com razão), Polkinghorne ainda fala em "uma medição transformar a potencialidade em realidade", de modo heisenberguiano! Se o nosso trirrealismo concerne a uma realidade configurada de maneira consequentemente triádica, somos levados a ver a) a "potencialidade" como Primeiridade, b) a "medição" e a "realidade" de Polkinghorne como Secundidade e c) a conceituação geral contida no seu livro (o citado Teoria quântica) como Terceiridade. Claro, a posição aqui apresentada é, em acordo com Peirce, a de um realismo semiótico, sempre subentendendo na expressão o triadismo envolvendo signo, objeto e interpretante, dependente das categorias cenopitagóricas. Mais claro ainda tudo isso apresentando-se como posição argumentada - decorrer, necessariamente, de uma perspectiva interessada, passível da crítica de uma perspectiva diversa, com os seus próprios argumentos. Como tal, o realismo semiótico-triádico é o "modelo de real multifacetado" que prometemos no primeiro parágrafo do nosso artigo. E, na sua combinação de peircianismo com mecânica quântica, ele abrange a ontologia e a epistemologia, retomando aqui os termos de F. S. Northrop.

Nós já mencionados Conceitos de física quântica, de Osvaldo Pessoa Jr., topamos com interessantes afirmativas de Max Born. Eis as suas palavras:

A questão de se as ondas são algo "real" ou uma ficção para descrever e prever fenômenos de maneira conveniente é uma questão de gosto. Eu [...] gosto de considerar uma onda de probabilidade, mesmo no espaço $3 \mathbf{N}$ dimensional, como uma coisa real, como certamente mais do que um instrumento para cálculos matemáticos. Pois ela tem a característica de um invariante de observação. (Apud PESSOA Jr., 2003, p. 97, grifo nosso)

Disponível em: http://seer.fclar.unesp.br/casa 
"Onda de probabilidade" e "Espaço 3N-dimensional" (de Hilbert): Primeiridade. "Observação": Secundidade. "Invariante": Terceiridade...

Bem ou mal, buscamos aqui sair da limitação da "questão de gosto", na caça da "coisa real", em boa hora invocada por Born.

\section{Por fim - ou necessariamente - em reinício}

Embora deixando alguns problemas interpretativos em aberto e não tendo a unidade que o termo induz a supor, o que poderíamos chamar de "o conjunto de elementos dominantes da Escola de Copenhague" passou para a história, por um bom tempo, como a "palavra final" sobre o mundo dos quanta, o que, de certa maneira, veio a criar alguns obstáculos para a tentativa de compreensão filosófica de tal mundo, algo que não se coaduna com a teorização de Peirce. Um obstáculo desse tipo foi a complementaridade ondapartícula, proposta por Niels Bohr, ${ }^{14}$ princípio segundo o qual não poderíamos saber o que existe para além desse dualismo, espécie de muro colocado perante o conhecimento humano. A própria história concreta da Física Quântica (com os seus problematizadores como Einstein, David Bohm, Hugh Everett III, John Bell, Dieter Zeh, etc.) viria a impedir, todavia, que os fatores mais "dogmáticos" da dita escola ficassem sem discussão. E nem se olvide que integrantes seus como Bohr, Heisenberg e Louis de Broglie repensaram conceitos da Interpretação de Copenhague (embora apenas a reflexão posterior do segundo desses três grandes cientistas nos parecesse apropriada a um paralelo maior com Peirce). Tudo isto, entre mais detalhes importantes, justifica o cotejo que intentamos.

Cotejo cujo valor heurístico caberá à comunidade de pesquisadores estabelecer. Reconhecendo que os dois domínios teóricos aqui correlacionados são densos em excesso, parece-nos boa ideia apontar, por meio de uma síntese, os aspectos deste artigo, os interpretantes dinâmicos verbais ora propostos, que precisam ser avaliados (sem prejuízo de outros pontos do mesmo texto também pedirem apreciação):

a) A hipótese de que as categorias peircianas e certas conceituações quânticas importantes podem ser correlacionadas. Esta alínea é passível de transformar-se num verbete didático da espécie: "Trirrealismo - Proposição de um realismo multifacetado, que combina a filosofia triádica de Peirce com a Física Quântica, segundo a versão de Copenhague, acrescida do mecanismo da descoerência. De acordo com tal combinação, o que chamamos realidade é constituído de, ao menos, três aspectos, que conduzem às correspondências entre a. 1) a Primeiridade e as ondas de possibilidade com vigência no espaço de Hilbert; a. 2) a Secundidade e o terreno das partículas detectadas, incluindo neste passo a matéria em estado de descoerência; a. 3) a Terceiridade e a esfera das leis que regem a Física Quântica (e a Clássica também, claro)". Não podemos, portanto, manter as mesmas expectativas epistêmicas em relação a estas três esferas do real - ou seja, é incorreto exigir que a.1) e a.3) seja analisáveis da maneira mais apropriada a a.2), e assim por diante, no âmago do triadismo considerado (isto sem deixar de ter no nosso intelecto a inter-relação dos três itens).

b) A suposição de que o indeterminismo de Peirce e o da Mecânica Quântica (o Princípio da Incerteza de Heisenberg, sobretudo) mereçam ser mais estudados em conjunto, a partir da sua aproximação já efetivada por Karl Popper.

\footnotetext{
${ }^{14}$ Muito abreviadamente: "Um fenômeno não pode ser ao mesmo tempo ondulatório e corpuscular" (PESSOA Jr., 2003: dest. noss.).
} 
c) A indicação de que as retomadas da aristotélica dýnamis-potencialidade, efetuadas por Peirce e depois, independentemente, por Heisenberg, careçam de maior atenção, também vistas em conjunto.

Pensamos que a alínea a) é o coração do realismo peirciano-quântico (plurifacetado, um trirrealismo, não mais "classicista"), aqui desenhado. Muito lógico, bastante natural que ele pulse de maneira semiótica.

\section{REFERÊNCIAS}

BITTAR, Eduardo B. Curso de filosofia aristotélica. Barueri, SP: Manole, 2003, 1442 p.

CAMPOS, Haroldo de (Org.). Ideograma: lógica, poesia, linguagem. Trad. Heloysa de Lima Dantas. São Paulo: Cultrix, 1977, 276 p.

FREIRE Jr., Olival et al. Teoria quântica: estudos históricos e implicações culturais. Campina Grande: EDUEP/Livraria da Física, 2010, 456 p.

GOBRY, Ivan. Vocabulário grego da filosofia. Trad. Ivone C. Benedetti. São Paulo: Martins Fontes, 2007, $168 \mathrm{p}$.

GOSWAMI, Amit. O universo autoconsciente. $2^{\text {a }}$. ed. $1^{\text {a }}$. reimpr. Trad. Ruy Jugmann. São Paulo: Aleph, 2010, 368 p.

HAWKING, Stephen. O universo numa casca de noz. Trad. Mônica Gagliotti Fortunato Friaça. São Paulo: Ediouro, 2009, 216 p.

HEISENBERG, Werner. Física e filosofia. $4^{\mathrm{a}}$. ed. Trad. Jorge Leal Ferreira. Brasília: Ed. da Universidade de Brasília, 1999, 296 p.

HERBERT, Nick. A realidade quântica. Trad. Mário C. Moura. Rio de Janeiro: Francisco Alves, 1989, $316 \mathrm{p}$.

HOOKWAY, Christopher. Peirce. London: Routledge \& Kegan, 1995, 310 p.

IBRI, Ivo Assad. Kósmos Noetós: a arquitetura metafísica de Charles Sanders Peirce. São Paulo: Perspectiva/Hólon, 1992, 140 p.

KAKU, Michio. Mundos paralelos. Trad. Talita M. Rodrigues. Rio de Janeiro: Rocco, 2007, $372 \mathrm{p}$.

KINOUCHI, Renato Rodrigues. Introdução. In: PEIRCE, Charles Sanders. Ilustrações da lógica da ciência. Trad. e introd. Renato Rodrigues Kinouchi. Aparecida, SP: Ideias e Letras, 2008, p. 7-30.

MESQUITA, Antônio Pedro. Aristóteles - obra completa: introdução geral. Lisboa: Imprensa Nacional-Casa da Moeda, 2005. Vol. I, t. I, 752 p.

NORTHROP, Filmer Stuart Cuckow. Introdução aos problemas da filosofia natural. In: HEISENBERG, Werner. Física e filosofia. $4^{\text {a }}$. ed. Trad. Jorge Leal Ferreira. Brasília: Ed. da Universidade de Brasília, 1999, p. 9-42.

OLIVEIRA, Ivan S. Física moderna. $2^{\mathrm{a}}$. ed. São Paulo: Livraria da Física, 2010, 304 p.

Revisitando a estranha natureza da realidade quântica. Ciência hoje. http://cienciahoje.uol.com.br/revista-ch/2011/282/revisitando-a-estranha-natureza-darealidade-quantica. Acesso em 06/09/2011, às 21h.

; VIEIRA, Cássio Leite. A revolução dos q-bits. Rio de Janeiro: Zahar, 2009, 160 p.

PEIRCE/FREGE. (Os pensadores). Trad. Armando Mora D'Oliveira et al. 3. ed. São Paulo: Abril Cultural, 1983, 284 p.

PEIRCE, Charles Sanders. Ilustrações da lógica da ciência. Trad. e introd. Renato Rodrigues Kinouchi. Aparecida, SP: Ideias e Letras, 2008, 200 p.

Semiótica. Trad. José Teixeira Coelho Netto. São Paulo: Perspectiva, 1977, 340 p. 
PESSOA Jr., O. Conceitos de física quântica. São Paulo: Ed. Livraria da Física, 2003. Vol. I e II, $332 \mathrm{p}$.

21/05/2013, às $10 \mathrm{~h}$.

PINTO, J. 1, 2, 3 da semiótica. Belo Horizonte: Editora UFMG, 1995, 70 p.

PINTO NETO, N. Teorias e interpretações da mecânica quântica. Rio de Janeiro: Rio de Janeiro: Centro Brasileiro de Pesquisas Físicas/São Paulo: Editora Livraria da Física, 2010, $160 \mathrm{p}$.

PIRES, J. L. V. P. de B. Panorama sobre a filosofia de Charles Sanders Peirce. www.unopar.br/portugues/revfonte/artigos/3charles/3charles.html. Acesso em 14/07/2012, às $14 \mathrm{~h}$.

POLKINGHORNE, J. Teoria quântica. Trad. Iuri Abreu. Porto Alegre: L\&PM, 2011, 144 p. POPPER, K. Conhecimento objetivo: uma abordagem evolucionária. Trad. Milton Amado. Belo Horizonte: Itatiaia, 1975, 272 p.

SEIFE, C. Decodificando o universo. Trad. Talita Rodrigues. Rio de Janeiro: Rocco, 2010, $320 \mathrm{p}$.

SANTAELLA, L. A assinatura das coisas: Peirce e a literatura. Rio de Janeiro: Imago, 1992, $215 \mathrm{p}$.

TUPYNAMBÁ, G. A. C. A ciência e a mente. Belo Horizonte: Coopmed, 2006, 216 p. 